\title{
Engineering Shewanella oneidensis enables xylose-fed microbial fuel cell
}

\author{
Feng Li ${ }^{1,2}$ (D), Yuanxiu Li ${ }^{1,2}$, Liming Sun ${ }^{3}$, Xiaofei Li ${ }^{1,2}$, Changji Yin ${ }^{1,2}$, Xingjuan An ${ }^{1,2}$, Xiaoli Chen ${ }^{1,2}$, Yao Tian ${ }^{1,2}$ \\ and Hao Song ${ }^{1,2^{*}}$
}

\begin{abstract}
Background: The microbial fuel cell (MFC) is a green and sustainable technology for electricity energy harvest from biomass, in which exoelectrogens use metabolism and extracellular electron transfer pathways for the conversion of chemical energy into electricity. However, Shewanella oneidensis MR-1, one of the most well-known exoelectrogens, could not use xylose (a key pentose derived from hydrolysis of lignocellulosic biomass) for cell growth and power generation, which limited greatly its practical applications.

Results: Herein, to enable S. oneidensis to directly utilize xylose as the sole carbon source for bioelectricity production in MFCs, we used synthetic biology strategies to successfully construct four genetically engineered S. oneidensis (namely XE, GE, XS, and GS) by assembling one of the xylose transporters (from Candida intermedia and Clostridium acetobutylicum) with one of intracellular xylose metabolic pathways (the isomerase pathway from Escherichia coli and the oxidoreductase pathway from Scheffersomyces stipites), respectively. We found that among these engineered $S$. oneidensis strains, the strain GS (i.e. harbouring GXf1 gene encoding the xylose facilitator from C. intermedi, and XYL1, $X Y L 2$, and XKS1 genes encoding the xylose oxidoreductase pathway from S. stipites) was able to generate the highest power density, enabling a maximum electricity power density of $2.1 \pm 0.1 \mathrm{~mW} / \mathrm{m}^{2}$.
\end{abstract}

Conclusion: To the best of our knowledge, this was the first report on the rationally designed Shewanella that could use xylose as the sole carbon source and electron donor to produce electricity. The synthetic biology strategies developed in this study could be further extended to rationally engineer other exoelectrogens for lignocellulosic biomass utilization to generate electricity power.

Keywords: Microbial fuel cell, Synthetic biology, Xylose, Shewanella oneidensis MR-1

\section{Background}

Bio-electrochemical systems enabled many practical applications in environments and energy fields [1-7], including microbial fuel cell (MFC) for simultaneous organic wastes treatment and electricity harvest [8-12], microbial electrolysis cells for hydrogen production [13-16], and microbial electrosynthesis for production of valuable chemicals from $\mathrm{CO}_{2}$ bioreduction [17-22]. Many mono-, di-saccharides as well as complex carbohydrates like starch and organics in wastewater and marine

\footnotetext{
*Correspondence: hsong@tju.edu.cn

${ }^{1}$ Key Laboratory of Systems Bioengineering (Ministry of Education),

School of Chemical Engineering and Technology, Tianjin University,

Tianjin 300072, China

Full list of author information is available at the end of the article
}

sediment have been used in MFCs for the production of electricity $[8,23,24]$. Xylose, one of primary ingredients from hydrolysis of lignocellulosic biomass, is the second most abundant carbohydrate after glucose in nature [2527]. Conversion of xylose to electricity energy using MFC would thus provide a sustainable and green energy, which received increased attention in recent few years [24, 2830]. However, xylose is hard to be effectively utilized by many microorganisms due to slow utilization rate and inefficient metabolic pathways of xylose [26, 31-35].

Shewanella oneidensis, one of the most well established metal-reducing exoelectrogens [36, 37], is capable of conducting extracellular electrons transfer (EET) through its metal-reducing (Mtr) pathway [38-42], being extensively studied for the optimization of MFC performance 
[40, 41, 43-47], MFC-based logic gate [48-50], bioremediation of toxic metals [51], etc., in recent decade. However, the wild-type (WT) S. oneidensis could only use three- (or two-) carbon substrates (e.g. lactate, pyruvate and acetate) as their carbon and energy sources, with an exception of N-acetyl-glucosamine (NAG) as a high-carbon carbohydrate $[45,52,53]$, while common pentoses or hexoses (e.g. xylose and glucose), the most abundant composition of biomass, could not be utilized by the WT S. oneidensis owing to its incomplete sugar utilization pathways $[36,54,55]$. Such defect enormously restricted the wide applications of $S$. oneidensis.

Recently, several strategies were developed to use xylose for electricity generation in Shewanella-inoculated MFCs. Firstly, an adaptive evolution approach was developed to activate an otherwise silent xylose metabolic pathway, i.e. oxidoreductase pathway in the WT S. oneidensis, thus generating a S. oneidensis mutant XM1 that could metabolize xylose as the sole carbon and energy source [56]. Secondly, microbial consortia including fermenters and exoelectrogens were developed to accomplish xylose-powered MFCs, in which the engineered Escherichia coli played as a fermenter to metabolize xylose for the synthesis of metabolites such as lactate and formate to feed the $S$. oneidensis as the carbon source and electron donor, thus enabling an indirect utilization of xylose by S. oneidensis for bioelectricity production [24].

Herein, we used synthetic biology strategy to rationally engineer $S$. oneidensis that could use xylose as the sole carbon source and electron donor for electricity generation in MFCs. To enable S. oneidensis to be able to use xylose, the xylose transporters (i.e. glucose/xylose facilitator encoded by gene Gxf1 from Candida intermedia [57, $58]$ and D-xylose-proton symporter encoded by gene $x y l T$ from Clostridium acetobutylicum [59]), synthetic isomerase pathway (including the genes $x y l A$ and $x y l B$ from $E$. coli [60]), and oxidoreductase (including from Scheffersomyces stipites [61]) pathway for xylose metabolism were heterologously expressed in S. oneidensis in a combinatorial way. Thus, four recombinant $S$. oneidensis strains were synthesized (see Fig. 1). Xylose-fed MFCs experiments proved that these engineered $S$. oneidensis MR-1 strains were conferred with the ability of utilizing xylose to produce electricity, and the engineered S. oneidensis strain GS provided the highest electricity generation. Compared with the $S$. oneidensis strain XM1 previously evolved by an adaptive evolution strategy [56], our rationally engineered S. oneidensis strains GS and XS (bearing the oxidoreductase pathway from S. stipites) showed a higher xylose consumption rate and a superior growth rate. In addition, the relative higher electricity generation by the GS strain than other engineered strains can be attributed to the higher intracellular riboflavin level and reducing equivalents in the GS. To the best of our knowledge, this was the first report on the rationally designed Shewanella that gained the expanded metabolic capability of using xylose as sole carbon source and electron donor to produce electricity.

\section{Results and discussion \\ Engineered xylose-utilizing S. oneidensis strain via synthetic biology strategies}

A few xylose metabolic pathways in microorganisms were found, including the oxidoreductase, isomerase, and Weimberg-Dahms pathways [56]. For example, E. coli is a robust and well-studied xylose scavenger [56, 62], which could metabolize xylose by the isomerase pathway; however, S. stipites [56, 61] could utilize oxidoreductase pathway for the metabolism of xylose. In the xylose isomerase pathway of $E$. coli $[56,60,63]$, xylose isomerase encoded by the gene $x y l A$ converts xylose to xylulose, which is then phosphorylated by xylulokinase encoded by the gene $x y l B$ to xylulose 5-phosphate (X-5-P), and then enters the pentose phosphate pathway (see Fig. 1). In the oxidoreductase pathway of S. stipites [26], NAD(P)H-dependent xylose reductase encoded by the gene $X Y L 1$ converts intracellular xylose to xylitol, which is then oxidized to xylulose by xylitol dehydrogenase (XDH) encoded by the gene XYL2. Xylulose is then phosphorylated by xylulokinase encoded by the gene XKS1 to xylulose 5-phosphate (X-5-P), which enters the pentose phosphate pathway, similar to the isomerase pathway (see Fig. 1).

To facilitate convenient and fast multigene assembly in S. oneidensis, a Biobrick compatible vector named pYYDT including an IPTG-inducible promoter PlacIq-lacIq-Ptac was well developed in our laboratory (Additional file 1: Figure S1B) [64]. Furthermore, to avoid the codon usage bias and prevent blocked translation due to shortage of tRNAs for rare codons between S. oneidensis and other bacteria, in vitro chemical synthesis of codon-optimized genes instead of direct cloning from other bacteria was used. The xylose metabolic pathway was then assembled by several routines of Biobrick ligation steps of the relevant genes. With the combinations of the two xylose transporters and the two xylose-utilizing metabolic pathways (the isomerase and the oxidoreductase pathways), four recombinant $S$. oneidensis strains harbouring engineered gene assembly (plasmid) for enhanced xylose transport and metabolism were synthesized, respectively, which were $\mathrm{XE}$ (including the gene $x y l T$ for xylose symporter, $x y l A$ and $x y l B$ for the xylose isomerase pathway), GE (including Gxf1 for the xylose facilitator, $x y l A$ and $x y l B$ for the xylose isomerase pathway), XS (including $x y l T$ for xylose symporter, and XYL1, XYL2, and XKS1 for the xylose oxidoreductase pathway), and GS (including Gxf1 for the xylose facilitator, and XYL1, XYL2, and XKS1 for the xylose oxidoreductase pathway). 


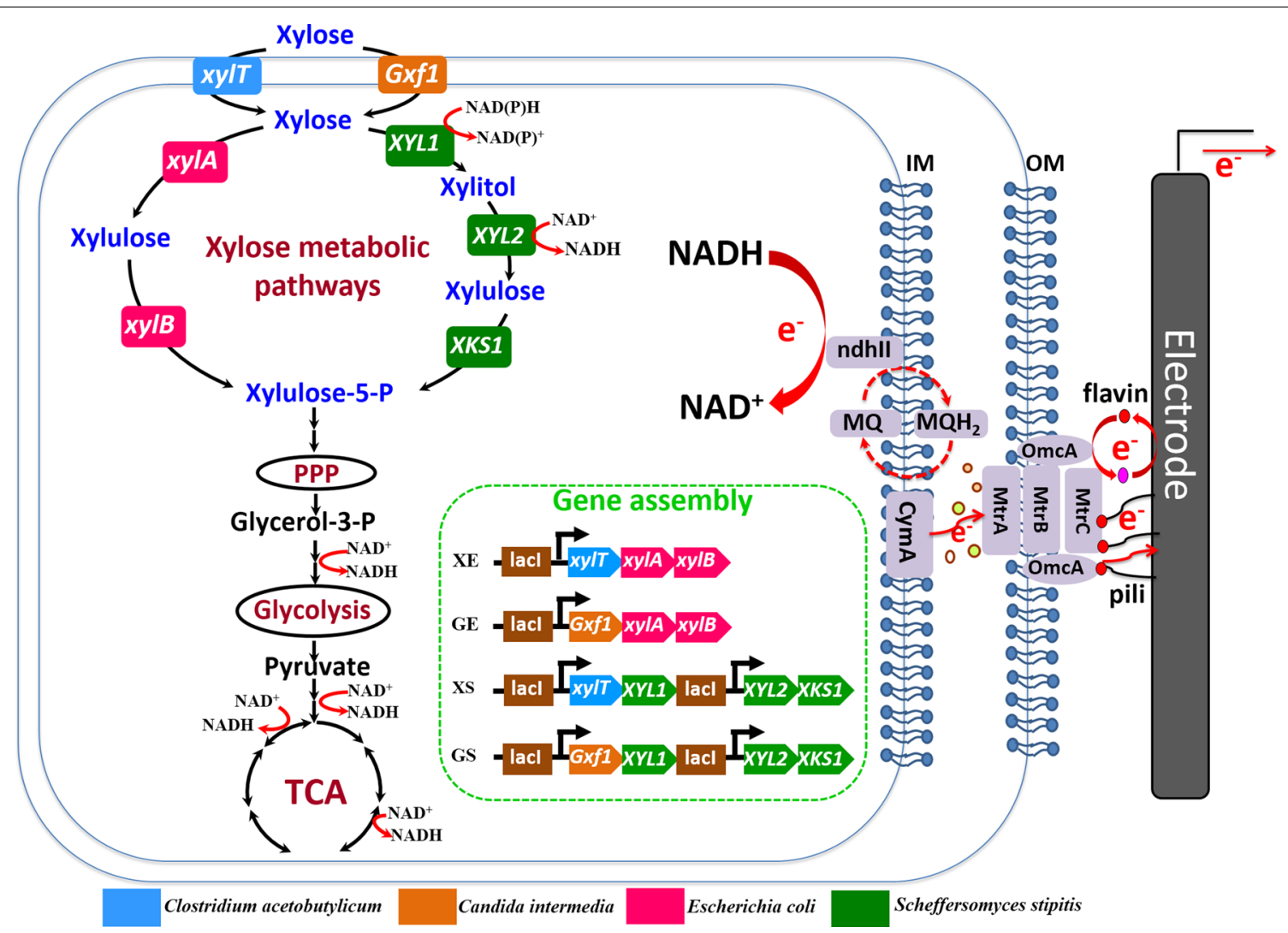

Fig. 1 Synthetic biology strategies for the construction of four recombinant S. oneidensis strains (namely XE, GE, XS, and GS) to enable xylose utilization and electricity generation of S. oneidensis. Xylose transporter genes included $x y / T$ (the gene encoding D-xylose-proton symporter) from Clostridium acetobutylicum and Gxf1 (the gene encoding glucose/xylose facilitator 1) from Candida intermedia. The xylose isomerase pathway included xylA (the gene encoding xylose isomerase) and $x y / B$ (the gene encoding xylulokinase) from E. coli. The oxidoreductase pathway included XYL1 (the gene encoding D-xylose reductase), XYL2 (the gene encoding xylitol dehydrogenase), and XKS1 (the gene encoding D-xylulokinase) from Scheffersomyces stipites. Four gene assemblies (plasmids), namely XE, GE, XS, and GS (as shown in the green-dash square) were synthesized for the enhanced xylose transport and metabolism, which transformed into $S$. oneidensis, respectively, to construct four recombinant $S$. oneidensis strains

\section{Evaluation of xylose utilization and cell growth of the recombinant $S$. oneidensis}

The cell growth and xylose consumption by the wild-type (WT, harbouring the pYYDT empty vector) and four genetically engineered $S$. oneidensis strains (i.e. harbouring XE, GE, XS, and GS, respectively) were evaluated in SBM supplemented with $5 \mathrm{mM}$ xylose as the sole carbon source.

Under aerobic conditions, the WT S. oneidensis strain showed almost no growth and xylose consumption, while the four engineered $S$. oneidensis strains showed a superior growth over the WT S. oneidensis strain. In addition, the growth rate of the engineered strains XS and GS (harbouring the oxidoreductase pathway) was faster than that of the strains XE and GE (harbouring the isomerase pathway) (Fig. 2a). The engineered strain XS and GS consumed xylose at a rate of $\sim 28.1$ and $\sim 35.2 \mu \mathrm{M} / \mathrm{h}$, which was faster than that of the engineered strains $\mathrm{XE}$ and $\mathrm{GE}$ $(\sim 11.2$ and $\sim 20.3 \mu \mathrm{M} / \mathrm{h})$ (Fig. $2 \mathrm{~b})$. Thus, the rate of xylose consumption of these engineered strains was in good agreement with that of the growth rate, respectively.

The anaerobic respiratory capabilities of the WT and the recombinant $S$. oneidensis were also determined under anaerobic conditions with xylose as the sole electron donor and fumarate as the electron acceptor. Similar to the aerobic conditions, the four genetically engineered strains grew faster than that of the WT strain. The recombinant strains XS and GS (harbouring the oxidoreductase pathway) consumed xylose at a rate of $\sim 14.8$, and $\sim 17.2 \mu \mathrm{M} / \mathrm{h}$, respectively, which had a faster xylose consumption rate than that of the strains $\mathrm{XE}$ and $\mathrm{GE}$ (harbouring the isomerase pathway, $\sim 6.3$ and $\sim 9.7 \mu \mathrm{M} / \mathrm{h}$, respectively) (Fig. 2c, d). Furthermore, the engineered strain GS could intake xylose faster than XS, which indicated that the glucose/xylose facilitator Gxf1 enabled a higher xylose transportation than that of the D-xyloseproton symporter XylT. It was revealed that sugar uptake via facilitated diffusion by Gxf1 required less energy 

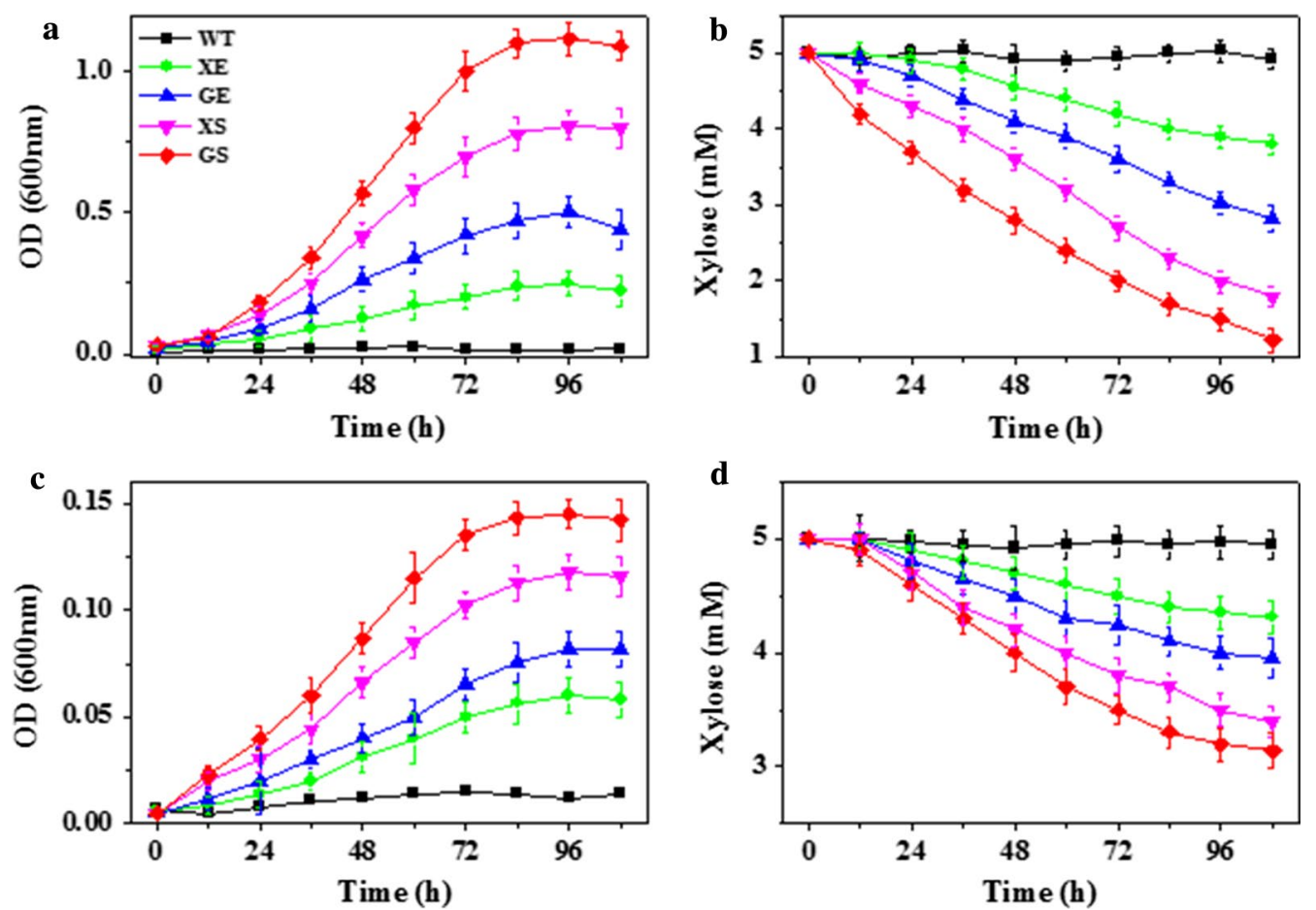

Fig. 2 Growth curves and xylose consumption of the WT and the recombinant S. oneidensis strains. a Aerobic growth curve $\left(\mathrm{OD}_{600} \sim \mathrm{t}\right)$ in SBM supplemented with $5 \mathrm{mM}$ xylose. b Xylose consumption under aerobic conditions. c Anaerobic growth curve $\left(\mathrm{OD}_{600} \sim \mathrm{t}\right)$ in SBM supplemented with $5 \mathrm{mM}$ xylose. $\mathbf{d}$ Xylose consumption under anaerobic conditions. The error bars were calculated from triplicate experiments

(ATP) than proton symport XylT, and thus the facilitator protein would probably be more efficient with higher substrate affinity under oxygen-limited or anaerobic conditions where ATP production is restricted in our MFC conditions $[58,65]$. In addition, all recombinant S. oneidensis strains were able to utilize lactate as the sole carbon source at a rate similar to that of the WT strain, suggesting that the lactate metabolism of S. oneidensis was not altered by such engineering efforts (data not shown).

Thus, our results indicated that the introduction of one of the synthetic xylose transporters (the D-xylose-proton symporter from C. acetobutylicum and the glucose/xylose facilitator from $C$. intermedia) and one of the metabolic pathways (i.e. the isomerase pathway from $E$. coli and the oxidoreductase pathways from S. stipites) could successfully confer Shewanella strains with the ability of utilizing xylose as the sole carbon source for the cell growth. Especially, our rationally designed $S$. oneidensis strains XS and GS (bearing the oxidoreductase pathway from S. stipites) showed a higher consumption of xylose and a superior growth rate than that of the $S$. oneidensis strain XM1 (that was recently developed through an adaptive evolution strategy) [56]. Escherichia coli (the BL21 strain) harbouring those genes related to xylose transport and metabolism exhibited a superior xylose consumption rate $(\sim 455 \mu \mathrm{M} / \mathrm{h})$, i.e. $\sim 12$ times faster than that of the engineered S. oneidensis GS $(\sim 35.2 \mu \mathrm{M} / \mathrm{h})$ (Additional file 1: Figure S2). This result indicated that although the engineered S. oneidensis was enabled the capability of xylose utilization, there was much room to further improve its xylose consumption rate by synthetic biology endeavours.

\section{MFC performance and bio-electrochemical analyses}

MFC was used to examine the extracellular electron transfer and power generation by the engineered S. oneidensis MR-1 using xylose as the sole carbon source. The WT and the engineered S. oneidensis strains were inoculated into the anodic chamber of MFCs, respectively, with a $2 \mathrm{k} \Omega$ external resistor, across which the voltage output was recorded.

Initially, $18 \mathrm{mM}$ lactate was used (as the favourable carbon source of Shewanella) to feed the engineered S. oneidensis strains in MFCs to verify the capacity of power output of each strain (Fig. 3). After the output voltage decreased to baseline levels (indicating the depletion of lactate), $18 \mathrm{mM}$ xylose was added into the anodic chamber as the carbon source. Obviously, the output voltages of these engineered S. oneidensis strains with xylose as the carbon source were lower than those of lactate as the carbon source, because lactate is the favourable carbon source 


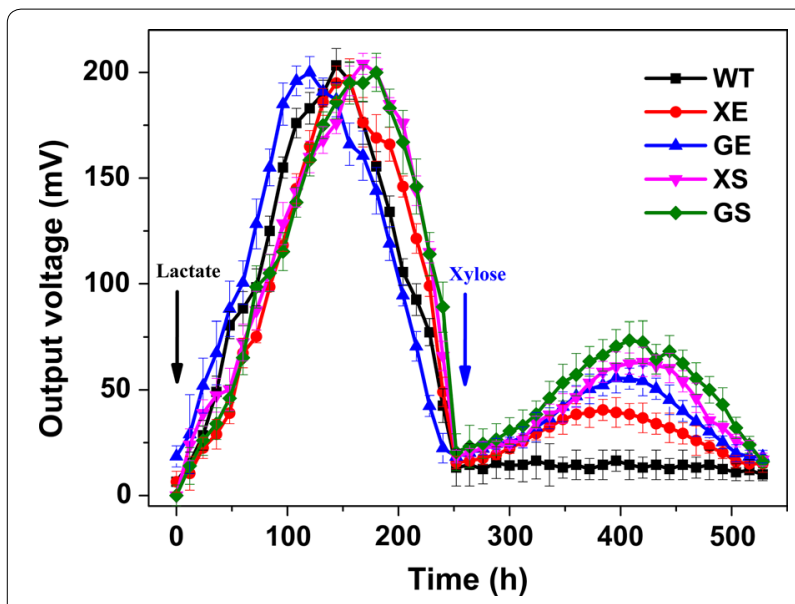

Fig. 3 Output voltage of the WT and four recombinant S. oneidensis strains (XE, GE, XS, and GS) with different carbon sources in the anodic chamber of MFCs. The output voltage of the four strains XE, GE, XS, and GS, using lactate and xylose as the carbon source, respectively. $18 \mathrm{mM}$ lactate (the favourable carbon source of Shewanella) was added at the initiation of MFC operations (as indicated by the black arrow). Upon the depletion of lactate and vanishing of electricity output, $18 \mathrm{mM}$ xylose was added at $\sim 260 \mathrm{~h}$ as the carbon source (as indicated by the blue arrow) to illustrate the power generation capability of these $S$. oneidensis strains using xylose as the sole carbon source. The error bars were calculated from triplicate experiments

for the growth and respiration of Shewanella (Fig. 3). When lactate was used as the carbon source, the maximum output voltages could increase to $\sim 205 \pm 7.2 \mathrm{mV}$ $(n=3)$ for both the WT and engineered S. oneidensis strains. However, the WT S. oneidensis strain could barely generate any voltage output when xylose was used as the carbon source, which indicated that the WT S. oneidensis could not utilize xylose. Upon genetic programming of the xylose transporter and metabolic pathway into S. oneidensis, the recombinant $S$. oneidensis strains, namely $\mathrm{XE}, \mathrm{GE}$, XS, and GS, could generate a maximum output voltage of $\sim 40.5 \pm 5.1, \sim 55.5 \pm 4.8, \sim 63.2 \pm 6.2$, and $\sim 73.4 \pm 5.8 \mathrm{mV}$ $(n=3)$, respectively. Furthermore, the multiple cycles of voltage output of these genetically engineered $S$. oneidensis strains showed the stability of power generation in the semi-batch xylose-fed MFCs (Fig. 4a).

We observed that the strains GS and XS harbouring the synthetic oxidoreductase xylose metabolic pathway could generate a higher voltage output than those of the XE and GE harbouring the synthetic isomerase xylose metabolic pathway (Fig. 4a). Bio-electrochemical analyses were further conducted to study the EET efficiency of these rationally engineered strains in MFCs. The cyclic voltammetry $(\mathrm{CV})$ at $1 \mathrm{mV} / \mathrm{s}$ was applied to reveal the redox reaction kinetics at the interfaces of bacterial cells and anodes. As shown in Fig. 4b, there were typical redox peaks of flavins in the CV curves starting from around $-0.4 \mathrm{~V}$ (vs. $\mathrm{Ag} / \mathrm{AgCl}$ ), which showed that flavins-mediated extracellular electron transfer was the dominating mechanism for bioelectricity production in these strains $[64,66]$. The power output curves (output voltage vs. current density) and the polarization curves (power density vs. current density), which were obtained by varying load resistances to show the dependence of voltage and power on the current, helped to further investigate the bioelectricity generation capability of the engineered S. oneidensis strains (Fig. 4c). Notably, the dropping slope of the polarization curve obtained from the engineered $S$. oneidensis strain GS (harbouring the xylose facilitator and the xylose oxidoreductase pathway) was smaller than those obtained from the other three engineered S. oneidensis stains (i.e. XE, GE, XS), implying that the internal charge transfer resistance of the MFC inoculated with GS was relatively smaller (Fig. 4c). The power density were calculated, which showed that the engineered $S$. oneidensis strain GS obtained a maximum power density of $\sim 2.1 \pm 0.1 \mathrm{~mW} / \mathrm{m}^{2}(n=3)$, which was $\sim 0.3, \sim 0.9, \sim 1.1$ times higher than that of XE, GE, and XS, respectively (Fig. 4c). Previous xylose-fed MFCs generally used sludge, natural or synthetic microbial consortia, the power generation of which were in the range of $6.3-2330 \mathrm{~mW} / \mathrm{m}^{2}$ (as shown in Additional file 2: Table $\mathrm{S} 1$ ), higher than that of our recombinant $S$. oneidensis strain. Thus, future engineering of Shewanella oneidensis to enable higher output electricity remained of paramount importance.

Biochemical characterizations showed that the engineered strains GS and XS had a higher utilization efficiency of xylose and higher growth rate, and a more efficient formation of biofilm attached on the anodes (Fig. 5a). Meanwhile, the engineered strains GS and XS could also generate higher intracellular reducing equivalents (i.e. NADH/NAD ${ }^{+}$, Fig. 5b). Such a high intracellular releasable electron pool (i.e. NADH) had resulted from the oxidative reaction of xylitol to xylulose, mediated by the reduction of $\mathrm{NAD}^{+}$to $\mathrm{NADH}$ in the oxidoreductase pathway [65, 67-69]. Both the efficient biofilm formation on the anodes [24, 70] and higher intracellular reducing equivalents $[71,72]$ in the engineered S. oneidensis strains GS and XS synergistically enabled an enhanced EET efficiency and electricity generation. In addition, an increase in the secretion of riboflavin in the recombinant strains also enabled an increase in the output voltage of MFCs. The increased biosynthesis of riboflavin would be attributed to the biosynthesis of xylulose 5-phosphate (X-5-P) owing to the heterologously introduced xylose metabolism pathway (i.e. the oxidoreductase pathway). X-5-P, as a metabolic product of the oxidoreductase pathway, was converted to ribulose-5-P, a crucial precursor for the biosynthesis of riboflavin, 


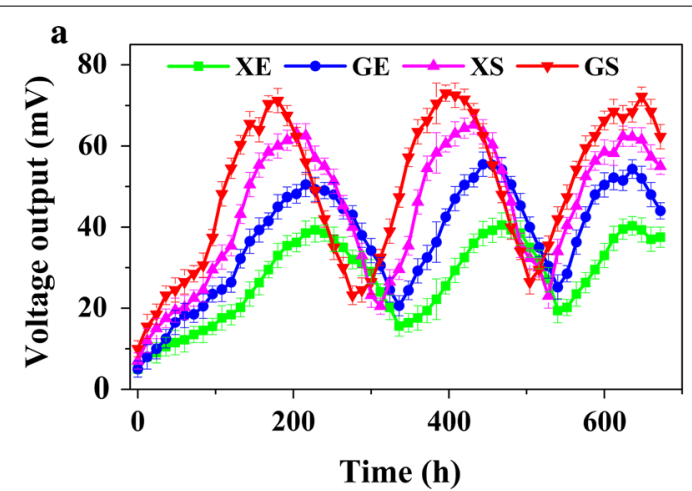

b
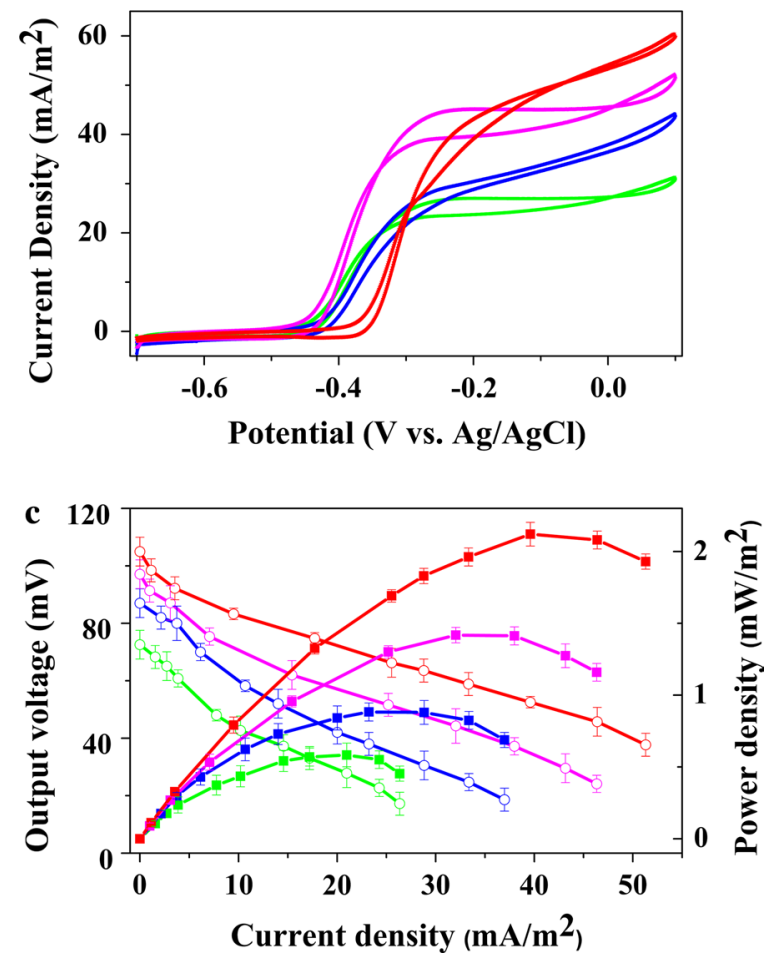

Fig. 4 Bio-electrochemical characterization of the extracellular electron transfer (EET) and electricity output capability of the four engineered S. oneidensis strains (namely XE, GE, XS, and GS) with xylose as the sole carbon source. $\mathbf{a}$ Voltage output of the four engineered $S$. oneidensis strains (XE, GE, XS, and GS) in the semi-batch xylose-fed multiple operational cycles of MFCs. Upon vanishing of electricity output and depletion of xylose at each MFC cycle, $18 \mathrm{mM}$ xylose was added to maintain the multiple MFC operation cycles. b Cyclic voltammetry (CV) at the scan rate of $1 \mathrm{mV} / \mathrm{s}$. c Polarization curves and power density output curves of the MFCs inoculated with the four recombinant $S$. oneidensis strains, respectively. The error bars were calculated from triplicate experiments

by ribulose-phosphate 3-epimerase encoded by the rpe gene in the pentose phosphate pathway. Subsequently, ribulose-5-P and guanosine triphosphate (GTP) were converted to riboflavin via the riboflavin biosynthesis pathway (Additional file 1: Figure S3) [24, 36, 53].

\section{Conclusions}

To the best of our knowledge, this research is the first to use synthetic biology strategy to rationally engineer $S$. oneidensis MR-1 to enable direct utilization of xylose as the sole carbon source and electron donor for bioelectricity production in MFCs. The efficient xylose metabolic pathways (the isomerase pathway or the oxidoreductase pathway) combined with two different xylose transporters were heterologously expressed in S. oneidensis MR-1 to construct four engineered S. oneidensis strains (namely XE, GE, XS, and GS), which could successfully utilize xylose under anaerobic and aerobic conditions. These recombinant $S$. oneidensis strains could generate bioelectricity in MFCs with xylose as the sole carbon source and electron donor. The maximum power density of the MFC inoculated with the engineered S. oneidensis strain GS (harbouring the xylose facilitator and the xylose oxidoreductase pathway) could reach $\sim 2.1 \pm 0.1 \mathrm{~mW} / \mathrm{m}^{2}$. This rationally engineered xylose transport and metabolic pathway significantly expanded the spectrum of carbon source that could be used by S. oneidensis. In the foreseeable future, with continuous development of synthetic biology strategies [73-75] to engineer exoelectrogens, a diverse array of organics such as lignocellulosic biomass and recalcitrant wastes may be more efficiently converted to electricity power.

\section{Methods}

\section{In vitro gene synthesis}

The information and coding sequences of the genes (Additional file 2: Tables S2 and S3) were extracted from the NCBI database and adapted for optimal expression in S. oneidensis MR-1 by a Java codon adaption tool (JCAT) in order to prevent blocked translation due to shortage of tRNAs for rare codons [49]. Each gene component was synthesized as a Biobrick [76, 77], and restriction enzyme sites of EcoRI, XbaI, SpeI, and SbfI were avoided in the codon-optimized sequences. The optimized gene sequence was flanked by an upstream prefix (containing EcoRI and $X b a \mathrm{I})$, a RBS site (BBa_B0034, iGEM) located at $6 \mathrm{bp}$ ahead of the start codon, and a downstream suffix (containing SpeI and Sbfl) (Additional file 1: Figure S1A). The designed gene sequences were synthesized in vitro, verified by Sanger sequencing (AuGCT, China).

\section{Plasmid construction, transformation, and culture conditions}

All plasmid constructions were performed in E. coli Trans T1. The E. coli strains were cultured in the LB (Luria-Bertani) medium at $37^{\circ} \mathrm{C}$ with $200 \mathrm{rpm}$. The plasmid to be transformed into $S$. oneidensis MR-1 (ATCC 700550) was firstly transformed into the plasmid donor strain E. coli WM3064 (auxotroph), and then transferred

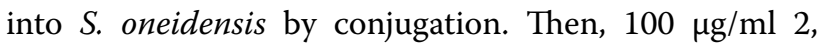



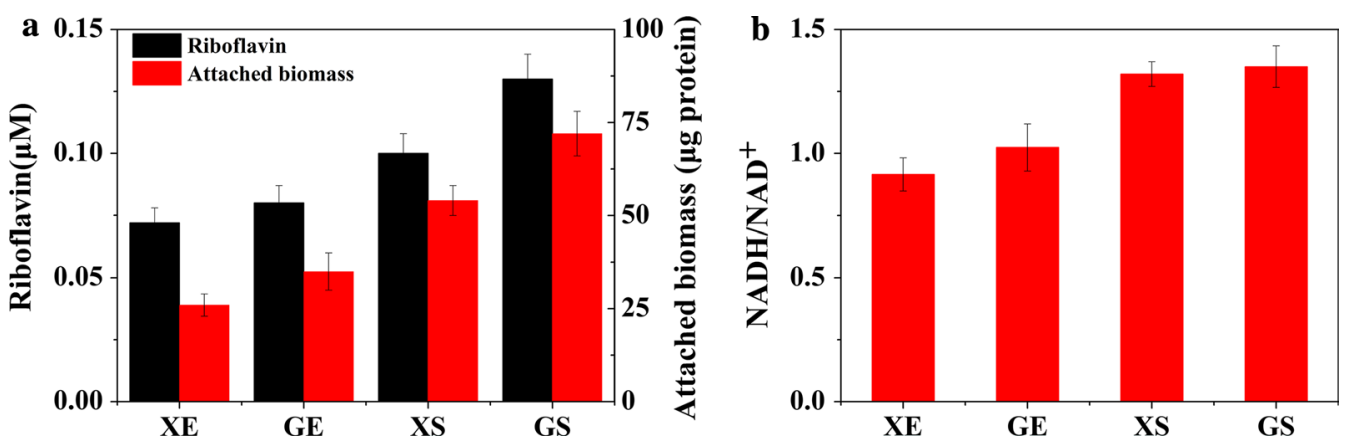

Fig. 5 Biochemical analyses of the four engineered S. oneidensis strains harbouring either the synthetic isomerase pathway (XE and GE) or the oxidoreductase pathway (XS and GS), respectively. a Riboflavin concentration in the anolytes of MFCs, and the attached biomass of each strain on anode surfaces. $\mathbf{b}$ Quantitative measurements of the ratio of NADH/NAD ${ }^{+}$in these engineered S. oneidensis strains in MFCs. All error bars were calculated from triplicate experiments

6-diaminopimelic acid (DAP) was added for the growth of $E$. coli WM3064. Whenever needed, $50 \mu \mathrm{g} / \mathrm{ml}$ kanamycin was added in the culture medium for plasmid maintenance. All the strains and plasmids used in this study are listed in Table (Additional file 2: Table S4).

\section{Determination of cell growth and xylose utilization}

To determine cell growth and xylose utilization under both aerobic and anaerobic conditions, $0.5 \mathrm{ml}$ of the wild-type (WT) or engineered xylose-utilizing S. oneidensis strain culture suspension was inoculated into $15 \mathrm{ml}$ Shewanella basal medium (SBM) [53] (Additional file 2: Table S5), supplemented with $5 \mathrm{mM}$ xylose as the electron donor and carbon source in the test tube. When needed, $10 \mathrm{mM}$ sodium fumarate was supplemented as the electron acceptor, which was stoichiometrically sufficient from both theoretical calculations and experimental validations (Additional file 1: Figure S4). The cell cultures were incubated at $30{ }^{\circ} \mathrm{C}$, and samples were withdrawn periodically for the determination of cell density (optical density at $600 \mathrm{~nm}$, i.e. $\mathrm{OD}_{600}$ ) and xylose consumption. The $\mathrm{OD}_{600}$ was measured by an ultraviolet and visible spectrophotometer (TU-1810, Beijing, China).

\section{BES setup}

To evaluate the efficiency of extracellular electron transfer (EET), the overnight Shewanella culture suspension $(1.5 \mathrm{ml})$ was inoculated into $150 \mathrm{ml}$ fresh LB broth at $30{ }^{\circ} \mathrm{C}$ with shaking $(200 \mathrm{rpm})$ till the $\mathrm{OD}_{600}$ reached $0.6-0.8$. Then, the cells were harvested by centrifugation and washed 3 times with fresh M9 buffer (Additional file 2: Table S6). The cell pellets were subsequently resuspended in $140 \mathrm{ml}$ electrolyte (5\% LB broth plus 95\% M9 buffer supplemented with $18 \mathrm{mM}$ lactate or xylose). $50 \mu \mathrm{g} / \mathrm{ml}$ kanamycin was added to ensure consistent culture condition. The medium was supplemented with $0.1 \mathrm{mM}$ IPTG as the inducer of the tac promoter. Our previous experiments proved that IPTG had no effect on the cell physiology and EET of Shewanella [70]. The dual-chamber MFCs were used in this study, namely the anodic and cathodic chambers $(140 \mathrm{ml}$ working volume) separated by the nafion 117 membrane (DuPont Inc., USA), were the same as those used in the previous study. Carbon cloth was used as the electrodes for both the anode $(2.5 \mathrm{~cm} \times 2.5 \mathrm{~cm}$, i.e. the geometric area is $\left.6.25 \mathrm{~cm}^{2}\right)$ and the cathode $(2.5 \mathrm{~cm} \times 3 \mathrm{~cm})$. The cathodic electrolyte consisted of $50 \mathrm{mM} \mathrm{K}_{3}\left[\mathrm{Fe}(\mathrm{CN})_{6}\right]$ in $50 \mathrm{mM}$ $\mathrm{K}_{2} \mathrm{HPO}_{4}$ and $50 \mathrm{mM} \mathrm{KH}_{2} \mathrm{PO}_{4}$ solution. To measure the voltage generation, a $2 \mathrm{k} \Omega$ external resistor was connected into the external circuit of MFCs, and the output voltage $(V)$ across the external loading resistor $(R)$ was measured by a digital multimeter (DT9205A).

\section{Electrochemical analyses}

Cyclic voltammetry (CV) was performed in a three-electrode configuration with an $\mathrm{Ag} / \mathrm{AgCl}$ reference electrode on a CHI $1000 \mathrm{C}$ multichannel potentiostat (CH Instrument, Shanghai, China). At the pseudo-steady state of MFCs, the polarization curves were obtained by varying the external resistor. Current density $(I)$ was calculated as $I=V$ (output voltage) $/ R$ (external resistance), and power density $(P)$ was calculated as $P=V \times I$. Then, the $I$ and $P$ were normalized to the projected geometric area of the anode to obtain the current density and power density, respectively [78].

\section{Quantification of metabolites}

For the quantification of riboflavin, the samples in the MFC supernatant were firstly centrifuged $(35,000 \mathrm{rpm}$ for $20 \mathrm{~min})$ and filtered $(0.22 \mu \mathrm{m})$, and then, the eluted media were detected by a liquid chromatograph-tandem mass spectrometer (LC-MS) (Agilent LCMS-1290-6460) in a positive ion mode using a Waters XBridge C8 column $(2.1 \times 100 \mathrm{~mm}$; particle size: $3.5 \mu \mathrm{m})$. Xylose in the 
anolytes were analysed using a high-performance liquid chromatography (HPLC) system equipped with a diode array detector. Sulphuric acid $(5 \mathrm{mM})$ was used as the mobile phase flowing at $0.6 \mathrm{ml} / \mathrm{min}$ through the Aminex HPX-87H column (Bio-Rad, USA), which was incubated at $50{ }^{\circ} \mathrm{C}$. Signals at $190 \mathrm{~nm}$ were used to quantify xylose.

\section{Quantification of intracellular NADH/NAD ${ }^{+}$}

Cells $(10 \mathrm{ml})$ were collected by centrifugation $(10,000 \mathrm{rpm}$ at $4{ }^{\circ} \mathrm{C}$ for $5 \mathrm{~min}$ ) and immediately re-suspended in $300 \mu \mathrm{l}$ of $0.2 \mathrm{M} \mathrm{HCl}$ (for $\mathrm{NAD}^{+}$) or $0.2 \mathrm{M} \mathrm{NaOH}$ (for NADH). The suspensions were boiled for $7 \mathrm{~min}$, rapidly quenched in an ice bath, and added with $300 \mu \mathrm{l}$ of $0.1 \mathrm{M} \mathrm{NaOH}\left(\right.$ for $\mathrm{NAD}^{+}$) or $0.1 \mathrm{M} \mathrm{HCl}$ (for $\mathrm{NADH}$ ). Cell debris was removed by centrifugation at 10,000 rpm for $10 \mathrm{~min}$, and the supernatant was used in a cycling assay to determine the amounts of $\mathrm{NAD}^{+}$and NADH $[79,80]$. Meanwhile, the cell concentration for the detection of $\mathrm{NAD}^{+}$and $\mathrm{NADH}$ concentration was detected by plate counts on LB agar.

\section{Measurement of electrode-attached biomass}

The electrode was placed in a $50-\mathrm{ml}$ tube containing $5 \mathrm{ml}$ of $0.2 \mathrm{~mol} / \mathrm{l} \mathrm{NaOH}$, then vortexed for $2 \mathrm{~min}$, and incubated in a water bath to lyse cells at $96{ }^{\circ} \mathrm{C}$ for $30 \mathrm{~min}$. The extracts were tested by bicinchoninic acid protein assay kit (Solarbio, China) after being cooled to room temperature.

\section{Additional files}

Additional file 1: Figure S1. Construction of synthetic xylose metabolic pathways in Shewanella oneidensis MR-1. (A) Schematic of the plasmid with a synthesized functional fragment of genes. The restriction sites EcoRI and Xbal with the ribosome binding site (RBS) are located upstream of each codon-optimized gene sequence, while the restrictions Spel and Pstl are located downstream of the gene. (B) Four plasmid constructs with xylose utilization pathways. To construct the multigene assembly in $S$. oneidensis, a Biobrick compatible expression vector PYYDT was adopted, which was previously constructed in our laboratory. Layout of the four plasmid constructs containing gene components in the xylose pathway examined in this study. Figure S2. Xylose consumption rate by E. coil (BL21) and by the recombinant $S$. oneidensis strain. The error bars were calculated from triplicate experiments. Figure $\mathbf{S 3}$. Metabolic pathway of riboflavin synthesis from xylose fermentation in S. oneidensis. A synthetic intracellular xylose metabolic pathway, i.e. the oxidoreductase pathway including genes XYL1, XYL2 and XKS1 from S. stipites, is incorporated into $S$. oneidensis MR-1 to enable the direct utilization of xylose. Xylulose 5-phosphate, as a metabolite in the oxidoreductase pathway, was converted to ribulose-5-P by ribulose-phosphate 3-epimerase (encoded by the rpe gene) in the pentose phosphate pathway, which was a crucial precursor for the biosynthesis of riboflavin via the riboflavin synthesis pathway. Figure S4. Xylose consumption under anaerobic conditions with 10 $\mathrm{mM}$ and $50 \mathrm{mM}$ fumarate. The error bars were calculated from triplicate experiments.

Additional file 2: Table S1. Summary of the reported energy output of Xylose-Fed MFCs. Table S2. Genes used in this study. Table S3. Synthesized sequences of genes in this study. Table S4. Strains and plasmids used in this study. Table S5. Main constituents for S. oneidensis basal medium (SBM). Table S6. Main constituents for M9 buffer.

\section{Abbreviations}

EET: extracellular electron transfer; MQ: methyl naphthoquinone; IM: inner membrane; OM: outer membrane; CymA: inner membrane tetraheme $c$-type cytochromes; Mtr: metal-reducing; MtrA: periplasmic decaheme; MtrB: $\beta$-barrel trans-OM protein; MtrC and OmcA: two OM decaheme $c$-type cytochromes; TCA: tricarboxylic acid cycle; ndhll: NADH dehydrogenase; P: phosphate; PEP: phosphoenol pyruvate; $\mathrm{NAD}^{+}$: nicotinamide adenine dinucleotide; $\mathrm{NADH}$ : reduced nicotinamide adenine dinucleotide; $\mathrm{NADP}^{+}$: nicotinamide adenine dinucleotide phosphate; NADPH: reduced nicotinamide adenine dinucleotide phosphate; ATP: adenosine triphosphate; ADP: adenosine diphosphate; X-5-P: xylulose 5-phosphate; GTP: guanosine triphosphate; IPTG: isopropyl $\beta$-D-1thiogalactopyranoside; DAP: 2, 6-diaminopimelic acid; MFC: microbial fuel cell; OD: optical density; CV: cyclic voltammetry; XDH: xylitol dehydrogenase; NAG: $\mathrm{N}$-acetyl-glucosamine.

\section{Authors' contributions}

FL designed the project, performed experiments, analysed data, and drafted the manuscript. YL, LS and XL performed some experiments, collected data, analysed data, and drafted the manuscript; CY, XA, XC and YT provided some reagents, helped design the experiment and drafted the manuscript; HS supervised the project, analysed the data, and critically revised the manuscript. All authors read and approved the final manuscript.

\section{Author details \\ ${ }^{1}$ Key Laboratory of Systems Bioengineering (Ministry of Education), School of Chemical Engineering and Technology, Tianjin University, Tianjin 300072, China. ${ }^{2}$ SynBio Research Platform, Collaborative Innovation Centre of Chemi- cal Science and Engineering, Tianjin University, Tianjin 300072, China. ${ }^{3}$ Pet- rochemical Research Institute, PetroChina Company Limited, Beijing 102206, People's Republic of China.}

\section{Acknowledgements}

Not applicable.

\section{Competing interests}

The authors declare that they have no competing interests.

\section{Availability of supporting data}

All data supporting the conclusions of this article are included within the manuscript and Additional files 1 and 2.

\section{Funding}

This research was supported by the National Natural Science Foundation of China (NSFC 21376174, 21621004), the National Basic Research Program of China ("973" Program: 2014CB745103), and Tianjin Science \& Technology Council (13JCYBJC40700).

\section{Publisher's Note}

Springer Nature remains neutral with regard to jurisdictional claims in published maps and institutional affiliations.

Received: 26 April 2017 Accepted: 1 August 2017

Published online: 08 August 2017

\section{References}

1. Butti SK, Velvizhi G, Sulonen MLK, Haavisto JM, Oguz Koroglu E, Yusuf Cetinkaya A, Singh S, Arya D, Annie Modestra J, Vamsi Krishna K, Verma A, Ozkaya B, Lakaniemi A-M, Puhakka JA, Venkata Mohan S. Microbial electrochemical technologies with the perspective of harnessing bioenergy: maneuvering towards upscaling. Renew Sust Energ Rev. 2016;53:462-76.

2. Mohan S, Butti S, Amulya K, Dahiya S, Modestra J. Waste biorefinery:a new paradigm for a sustainable bioelectro economy. Trends Biotechnol. 2016;34(11):852-5.

3. Xie X, Ye M, Hsu PC, Liu N, Criddle CS, Cui Y. Microbial battery for efficient energy recovery. Proc Natl Acad Sci. 2013;110(40):15925-30. 
4. Wang H, Luo H, Fallgren PH, Jin S, Ren ZJ. Bioelectrochemical system platform for sustainable environmental remediation and energy generation. Biotechnol Adv. 2015;33(3-4):317-34.

5. Wang H, Ren ZJ. A comprehensive review of microbial electrochemical systems as a platform technology. Biotechnol Adv. 2013;31(8):1796-807.

6. Harnisch F, Schroder U. From MFC to MXC: chemical and biological cathodes and their potential for microbial bioelectrochemical systems. Chem Soc Rev. 2010;39(11):4433-48.

7. Kumar A. The ins and outs of microorganism-electrode electron transfer reactions. Nat Rev Chem. 2017;1 (3):0024.

8. Chaudhuri S, Lovley D. Electricity generation by direct oxidation of glucose in mediatorless microbial fuel cells. Nat Biotechnol. 2003;21(10):1229-32.

9. Logan BE. Exoelectrogenic bacteria that power microbial fuel cells. Nat Rev Microbiol. 2009;7(5):375-81.

10. Lovley DR. Bug juice: harvesting electricity with microorganisms. Nat Rev Microbiol. 2006;4(7):497-508.

11. Logan BE, Rabaey K. Conversion of wastes into bioelectricity and chemicals by using microbial electrochemical technologies. Science. 2012:337(6095):686-90.

12. Bond DR, Holmes DE, Tender LM, Lovley DR. Electrode-reducing microorganisms that harvest energy from marine sediments. Science. 2002;295(5554):483

13. Jafary T, Wan RWD, Ghasemi M, Kim BH, Jahim JM, Ismail M, Lim SS. Biocathode in microbial electrolysis cell: present status and future prospects. Renew Sust Energ Rev. 2015;47:23-33.

14. Luo H, Jenkins PE, Zen Z. Concurrent desalination and hydrogen generation using microbial electrolysis and desalination cells. Environ Sci Technol. 2011:45(1):340-4.

15. Mehanna M, Kiely PD, Call DF, Logan BE. Microbial electrodialysis cell for simultaneous water desalination and hydrogen gas production. Environ Sci Technol. 2010;44(24):9578-83.

16. Zhang Y, Angelidaki I. Microbial electrolysis cells turning to be versatile technology: recent advances and future challenges. Water Res. 2014;56(3):11-25.

17. Rabaey K, Rozendal RA. Microbial electrosynthesis-revisiting the electrical route for microbial production. Nat Rev Microbiol. 2010;8(10):706-16.

18. Han L, Opgenorth PH, Wernick DG, Rogers S, Wu TY, Higashide W, Malati $\mathrm{P}$, Huo YX, Cho KM, Liao JC. Integrated electromicrobial conversion of $\mathrm{CO}_{2}$ to higher alcohols. Science. 2012;335(6076):1596.

19. Sakimoto KK, Wong AB, Yang P. Self-photosensitization of nonphotosynthetic bacteria for solar-to-chemical production. Science. 2016;351(6268):74-7.

20. Liu C, Colon BC, Ziesack M, Silver PA, Nocera DG. Water splitting-biosynthetic system with $\mathrm{CO}_{2}$ reduction efficiencies exceeding photosynthesis. Science. 2016;352(6290):1210-3.

21. Sadhukhan J, Lloyd JR, Scott K, Premier GC, Yu EH, Curtis T, Head IM. A critical review of integration analysis of microbial electrosynthesis (MES) systems with waste biorefineries for the production of biofuel and chemical from reuse of $\mathrm{CO}_{2}$. Renew Sust Energ Rev. 2016;56:116-32.

22. Choi O, Sang BI. Extracellular electron transfer from cathode to microbes: application for biofuel production. Biotechnol Biofuels. 2016;9(1):1-14.

23. Lin T, Bai X, Hu Y, Li B, Yuan Y, Song H, Yang Y, Wang J. Synthetic Saccharomyces cerevisiae-Shewanella oneidensis consortium enables glucose-fed high-performance microbial fuel cell. AIChE J. 2016.

24. Yang $Y$, Wu Y, Hu Y, Cao Y, Poh $\mathrm{CL}$, Cao B, Song H. Engineering electrodeattached microbial consortia for high-performance xylose-fed microbial fuel cell. ACS Catal. 2015;5(11):6937-45.

25. Rubin EM. Genomics of cellulosic biofuels. Nature. 2008;454(7206):841-5.

26. Kuhad RC, Gupta R, Khasa YP, Singh A, Zhang YHP. Bioethanol production from pentose sugars: current status and future prospects. Renew Sust Energ Rev. 2011;15(9):4950-62.

27. Jackson S, Nicolson S. Xylose as a nectar sugar: from biochemistry to ecology. Comp Biochem Phys B. 2002;131(4):613-20.

28. Catal T, Li K, Bermek H, Liu H. Electricity production from twelve monosaccharides using microbial fuel cells. J Power Sources. 2008;175(1):196-200.

29. Huang L, Logan BE. Electricity production from xylose in fed-batch and continuous-flow microbial fuel cells. Appl Microbiol Biotechnol. 2008;80(4):655-64.

30. Huang L, Zeng RJ, Angelidaki I. Electricity production from xylose using a mediator-less microbial fuel cell. Bioresour Technol. 2008;99(10):4178-84.
31. Utrilla J, Licona-Cassani C, Marcellin E, Gosset G, Nielsen LK, Martinez A. Engineering and adaptive evolution of escherichia coli, for D-lactate fermentation reveals gatc as a xylose transporter. Metab Eng. 2012;14(5):469-76.

32. Zhou H, Cheng JS, Wang BL, Fink GR, Stephanopoulos G. Xylose isomerase overexpression along with engineering of the pentose phosphate pathway and evolutionary engineering enable rapid xylose utilization and ethanol production by Saccharomyces cerevisiae. Metab Eng. 2012;14(6):611-22.

33. Young EM, Comer AD, Huang H, Alper HS. A molecular transporter engineering approach to improving xylose catabolism in Saccharomyces cerevisiae. Metab Eng. 2012;14(4):401.

34. Yuan Y, Du J, Zhao H. Customized optimization of metabolic pathways by combinatorial transcriptional engineering. Nucleic Acids Res. 2012:40(18):177-209.

35. Xiao H, Li Z, Jiang Y, Yang Y, Jiang W, Gu Y, Yang S. Metabolic engineering of d-xylose pathway in Clostridium beijerinckii to optimize solvent production from xylose mother liquid. Metab Eng. 2012;14(5):569.

36. Fredrickson JK, Romine MF, Beliaev AS, Auchtung JM, Driscoll ME, Gardner TS, Nealson KH, Osterman AL, Pinchuk G, Reed JL, Rodionov DA, Rodrigues JL, Saffarini DA, Serres MH, Spormann AM, Zhulin IB, Tiedje JM. Towards environmental systems biology of Shewanella. Nat Rev Microbiol. 2008;6(8):592-603.

37. Kumar R, Singh L, Zularisam AW. Exoelectrogens: recent advances in molecular drivers involved in extracellular electron transfer and strategies used to improve it for microbial fuel cell applications. Renew Sust Energ Rev. 2016;56:1322-36.

38. Coursolle D, Gralnick JA. Modularity of the Mtr respiratory pathway of Shewanella oneidensis strain MR-1. Mol Microbiol. 2010;77(4):995-1008.

39. Okamoto A, Nakamura R, Hashimoto K. In-vivo identification of direct electron transfer from Shewanella oneidensis MR-1 to electrodes via outer-membrane OmcA-MtrCAB protein complexes. Electrochim Acta. 2011:56(16):5526-31.

40. Hartshorne RS, Reardon CL, Ross D, Nuester J, Clarke TA, Gates AJ, Mills PC, Fredrickson JK, Zachara JM, Shi L, Beliaev AS, Marshall MJ, Tien M, Brantley S, Butt JN, Richardson DJ. Characterization of an electron conduit between bacteria and the extracellular environment. Proc Natl Acad Sci. 2009;106(52):22169-74.

41. Clarke TA, Richardson DJ. Structure of a bacterial cell surface decaheme electron conduit. Proc Natl Acad Sci. 2011;108(23):9384-9.

42. Mao L, Verwoerd WS. Theoretical exploration of optimal metabolic flux distributions for extracellular electron transfer by Shewanella oneidensis MR-1. Biotechnol Biofuels. 2014;7(1):1-20.

43. El-Naggar MY, Wanger G, Leung KM, Yuzvinsky TD, Southam G, Yang J, Lau WM, Nealson KH, Gorby YA. Electrical transport along bacterial nanowires from Shewanella oneidensis MR-1. Proc Natl Acad Sci. 2010;107(42):18127-31.

44. Okamoto A, Hashimoto K, Nealson KH, Nakamura R. Rate enhancement of bacterial extracellular electron transport involves bound flavin semiquinones. Proc Natl Acad Sci. 2013;1 10(19):7856-61.

45. Pinchuk GE, Rodionov DA, Yang C, Li X, Osterman AL, Dervyn E, Geydebrekht OV, Reed SB, Romine MF, Collart FR, Scott JH, Fredrickson JK, Beliaev AS. Genomic reconstruction of Shewanella oneidensis MR-1 metabolism reveals a previously uncharacterized machinery for lactate utilization. Proc Natl Acad Sci. 2009;106(8):2874-9.

46. Pirbadian S, Barchinger SE, Leung KM, Byun HS, Jangir Y, Bouhenni RA, Reed SB, Romine MF, Saffarini DA, Shi L, Gorby YA, Golbeck JH, El-Naggar MY. Shewanella oneidensis MR-1 nanowires are outer membrane and periplasmic extensions of the extracellular electron transport components. Proc Natl Acad Sci. 2014;111(35):12883-8.

47. White GF, Shi Z, Shi L, Wang Z, Dohnalkova AC, Marshall MJ, Fredrickson JK, Zachara JM, Butt JN, Richardson DJ, Clarke TA. Rapid electron exchange between surface-exposed bacterial cytochromes and Fe(III) minerals. Proc Natl Acad Sci. 2013;1 10(16):6346-51.

48. Hu Y, Wu Y, Mukherjee M, Cao B. A near-infrared light responsive c-di-GMP module-based AND logic gate in Shewanella oneidensis. Chem Commun. 2017;53:1646-8.

49. Hu Y, Yang $Y$, Katz E, Song H. Programming the quorum sensing-based AND gate in Shewanella oneidensis for logic gated-microbial fuel cells. Chem Commun. 2015;51(20):4184-7. 
50. Li Z, Rosenbaum MA, Venkataraman A, Tam TK, Katz E, Angenent LT. Bacteria-based AND logic gate: a decision-making and self-powered biosensor. Chem Commun. 2011;47(11):3060-2.

51. Ding Y, Peng N, Du Y, Ji L, Cao B. Disruption of putrescine biosynthesis in Shewanella oneidensis enhances biofilm cohesiveness and performance in $\mathrm{Cr}(\mathrm{VI})$ Immobilization. Appl Environ Microbiol. 2013;80(4):1498-506.

52. Serres MH, Riley M. Genomic analysis of carbon source metabolism of Shewanella oneidensis MR-1: predictions versus experiments. J Bacteriol. 2006;188(13):4601-9.

53. Flynn CM, Hunt KA, Gralnick JA, Srienc F. Construction and elementary mode analysis of a metabolic model for Shewanella oneidensis MR-1. Biosystems. 2012;107(2):120-8.

54. Pinchuk GE, Geydebrekht OV, Hill EA, Reed JL, Konopka AE, Beliaev AS, Fredrickson JK. Pyruvate and lactate metabolism by Shewanella oneidensis MR-1 under fermentation, oxygen limitation, and fumarate respiration conditions. Appl Environ Microbiol. 2011;77(23):8234-40.

55. Pinchuk GE, Hill EA, Geydebrekht OV, De Ingeniis J, Zhang X, Osterman A, Scott JH, Reed SB, Romine MF, Konopka AE, Beliaev AS, Fredrickson JK, Reed JL. Constraint-based model of Shewanella oneidensis MR-1 metabolism: a tool for data analysis and hypothesis generation. PLoS Comput Biol. 2010;6(6):e1000822.

56. Sekar R, Shin HD, DiChristina TJ. Activation of an otherwise silent xylose metabolic pathway in Shewanella oneidensis. Appl Environ Microbiol. 2016;82(13):3996-4005.

57. Runquist D, Fonseca C, Radstrom P, Spencer-Martins I, Hahn-Hagerdal B. Expression of the Gxf1 transporter from Candida intermedia improves fermentation performance in recombinant xylose-utilizing Saccharomyces cerevisiae. Appl Microbiol Biotechnol. 2009;82(1):123-30.

58. Leandro MJ, Goncalves P, Spencer-Martins I. Two glucose/xylose transporter genes from the yeast Candida intermedia: first molecular characterization of a yeast xylose- $\mathrm{H}^{+}$symporter. Biochem J. 2006;395(3):543-9.

59. Gu Y, Ding Y, Ren C, Sun Z, Rodionov DA, Zhang W, Yang S, Yang C, Jiang W. Reconstruction of xylose utilization pathway and regulons in Firmicutes. BMC genomics. 2010;11:255.

60. Zhang M, Eddy C, Deanda K, Finkelstein M, Picataggio S. Metabolic Engineering of a pentose metabolism pathway in ethanologenic Zymomonas mobilis. Science. 1995;267(5195):240-3.

61. Jeffries TW, Grigoriev IV, Grimwood J, Laplaza JM, Aerts A, Salamov A, Schmutz J, Lindquist E, Dehal P, Shapiro H, Jin YS, Passoth V, Richardson PM. Genome sequence of the lignocellulose-bioconverting and xylosefermenting yeast Pichia stipitis. Nat Biotechnol. 2007;25(3):319-26.

62. Nduko JM, Matsumoto K, Ooi T, Taguchi S. Effectiveness of xylose utilization for high yield production of lactate-enriched P(lactate-co-3-hydroxybutyrate) using a lactate-overproducing strain of Escherichia coli and an evolved lactate-polymerizing enzyme. Metab Eng. 2013;15:159-66.

63. Wovcha MG, Steuerwald DL, Brooks KE. Amplification of d-xylose and D-glucose isomerase activities in Escherichia coli by gene cloning. Appl Environ Microbiol. 1983;45(4):1402.
64. Yang Y, Ding Y, Hu Y, Cao B, Rice SA, Kjelleberg S, Song H. Enhancing bidirectional electron transfer of Shewanella oneidensis by a synthetic flavin pathway. ACS Synth Biol. 2015;4(7):815-23.

65. Jeffries TW. Engineering yeasts for xylose metabolism. Curr Opin Biotech. 2006;17(3):320-6.

66. Baron D, LaBelle E, Coursolle D, Gralnick JA, Bond DR. Electrochemical measurement of electron transfer kinetics by Shewanella oneidensis MR-1. J Biol Chem. 2009;284(42):28865-73.

67. Verho R, Londesborough J, Penttila M, Richard P. Engineering redox cofactor regeneration for improved pentose fermentation in Saccharomyces cerevisiae. Appl Environ Microbiol. 2003;69(10):5892-7.

68. Kuyper M, Winkler AA, van Dijken JP, Pronk JT. Minimal metabolic engineering of Saccharomyces cerevisiae for efficient anaerobic xylose fermentation: a proof of principle. FEMS Yeast Res. 2004;4(6):655-64.

69. Kim SR, Ha SJ, Kong II, Jin YS. High expression of XYL2 coding for xylitol dehydrogenase is necessary for efficient xylose fermentation by engineered Saccharomyces cerevisiae. Metab Eng. 2012;14(4):336-43.

70. Liu T, Yu YY, Deng XP, Ng CK, Cao B, Wang JY, Rice SA, Kjelleberg S, Song $H$. Enhanced Shewanella biofilm promotes bioelectricity generation. Biotechnol Bioeng. 2015;112(10):2051-9.

71. Han S, Gao X, Ying H, Zhou CC. NADH gene manipulation for advancing bioelectricity in Clostridium ljungdahlii microbial fuel cells. Green Chem. 2016;18(8):2473-8.

72. Yong $Y C$, Yu YY, Yang $Y$, Li CM, Jiang $R$, Wang $X Y$, Wang J, Song $H$. Increasing intracellular releasable electrons dramatically enhances bioelectricity output in microbial fuel cells. Electrochem Commun. 2012;19:13-6.

73. Jensen HM, Cantor CR. Engineering of a synthetic electron conduit in living cells. Proc Natl Acad Sci. 2010;107(45):19213-8.

74. TerAvest MA, Ajo-Franklin CM. Transforming exoelectrogens for biotechnology using synthetic biology. Biotechnol Bioeng. 2016;113(4):687-97.

75. Jensen H, Teravest M, Kokish M, Ajofranklin CM. CymA and exogenous flavins improve extracellular electron transfer and couple it to cell growth in Mtr-expressing Escherichia coli. ACS Synth Biol. 2016;5(7):679-88.

76. Tsvetanova B, Peng L, Liang X, Li K, Yang JP, Ho T, Shirley J, Xu L, Potter J, Kudlicki W, Peterson T, Katzen F. Genetic assembly tools for synthetic biology. Methods Enzymol. 2011;498:327-48.

77. Ellis T, Adie T, Baldwin GS. DNA assembly for synthetic biology: from parts to pathways and beyond. Integr Biol (Camb). 2011;3:109-18.

78. Yong $Y C$, Yu YY, Zhang $X$, Song $H$. Highly active bidirectional electron transfer by a self-assembled electroactive reduced-graphene-oxidehybridized biofilm. Angew Chem Int Ed. 2014;53(17):4480-3.

79. Yong XY, Feng J, Chen YL, Shi DY, Xu YS, Zhou J, Wang SY, Xu L, Yong YC, Sun YM, Shi CL, OuYang PK, Zheng T. Enhancement of bioelectricity generation by cofactor manipulation in microbial fuel cell. Biosens Bioelectron. 2014;56:19-25.

80. Bernofsky C, Swan M. An improved cycling assay for nicotinamide adenine dinucleotide. Anal Biochem. 1973;53(2):452-8.

\section{Submit your next manuscript to BioMed Central and we will help you at every step:}

- We accept pre-submission inquiries

- Our selector tool helps you to find the most relevant journal

- We provide round the clock customer support

- Convenient online submission

- Thorough peer review

- Inclusion in PubMed and all major indexing services

- Maximum visibility for your research

Submit your manuscript at www.biomedcentral.com/submit 